\title{
Exploration on the Teaching Practice of Entrepreneurship Management Course in Business Universities
}

\author{
Yonghui Dai * \\ Management School \\ Shanghai University of International Business and Economics \\ Shanghai, China
}

Qianfeng Zhu

Management School

Shanghai University of International Business and Economics Shanghai, China

\author{
Nianwen Du \\ Management School \\ Shanghai University of International Business and Economics \\ Shanghai, China \\ Peng Zuo \\ Management School \\ Shanghai University of International Business and Economics \\ Shanghai, China
}

\begin{abstract}
Innovative entrepreneurship education has attracted the attention of colleges and universities as a national strategy. The work explores the curriculum teaching practice of 320 entrepreneurial management students of Shanghai University of International Business and Economics. And the results show that the entrepreneurship management curriculum mainly faces two major problems: professional teachers and academic environment. Meanwhile, students believe that the curriculum should focus on vocational ability training and solving the current problem of employment. Our research provides a reference for improving the teaching effect of entrepreneurship management.
\end{abstract}

Keywords-innovation and entrepreneurship; entrepreneurship management; course teaching; academic environment

\section{INTRODUCTION}

The concept of innovation and entrepreneurship education was first proposed by Japan in the 1990s. It refers to the cultivation of people with developmental personality, including the spirit of innovation, adventure, and self-employment. In 2014, China issued the call of "Mass entrepreneurship and innovation", and at the 18th National Congress of the Communist Party of China (CPC), the innovation-driven development strategy was regarded as an important strategic plan affecting the national economy, marking that China's innovation and entrepreneurship entered a new stage.

As the main force of innovation and entrepreneurship, it's essential for contemporary college students to cultivate their sense of innovation and hone their entrepreneurial spirit. The current research on entrepreneurship management courses focuses on the discussion of entrepreneurial management practice teaching and case teaching. Yang et al (2018) explained the main problems faced by the current innovation and entrepreneurship curriculum from the problems faced by the current dual-innovation curriculum, reform countermeasures and the reform objectives. The main problems faced by the current innovation and entrepreneurship

This work is supported by the project of Shanghai Higher Education Society under Grant (No. GJEL1851). curriculum include the single curriculum, imperfect practice, and lack of practice in student entrepreneurship. The strategy of reformation can be proposed in three dimensions: teaching students in accordance with their aptitude, software-assisted teaching, and practical training [1]; Guo (2017) combines the curriculum teaching practice with the orientation of the innovative and entrepreneurial teaching curriculum, the design of entrepreneurial competence matrix, and the reform experiment of task-driven teaching. And the improvement effect of entrepreneurship management courses [2]; Zhang et al (2017) proposed to improve the entrepreneurial education system, cultivate high-level competence as the goal of curriculum construction, and divide the high-level entrepreneurial ability into thinking ability, innovation ability, problem solving ability, decision-making ability, critical thinking ability, perfecting the entrepreneurial education system from building a faculty, building a simulation platform, and encouraging campus entrepreneurial activities [3]. The article takes 320 students from the Shanghai University of International Business and Economics as the research object and seeks students' views on the problems faced at the current stage of the entrepreneurship management course and the practical teaching opinions on the course. From the perspective of training objectives and teaching methods, the author constructs entrepreneurship management course practice teaching mode.

\section{The PROBlems Faced By PRACTICAL TEACHING}

A. The teacher issues of entrepreneurship management

1) A shortage of professional teachers

One of the common problems faced by entrepreneurial management disciplines as emerging disciplines is the weak teachers. At present, there are few authoritative experts in the entrepreneurial management courses of major universities in China. Most of the teachers' professional title evaluations are based on the original disciplines. Most of the college teachers are from the school to the school process. The teachers themselves often lack the real entrepreneurial practice 
experience; theoretical knowledge may not be able to meet the ever-changing entrepreneurial problems. Due to the lack of thinking and experience of professional teachers, it is difficult to complete the goal of entrepreneurial management teaching in teaching work, and practical teaching is more difficult.

2) Deviation of entrepreneurial management education concept

There are widespread misunderstandings in entrepreneurial management teachers in colleges and universities. This misunderstanding is also the misconception of current students or entrepreneurial groups. Some educators simply understand entrepreneurship management courses as courses that encourage students or entrepreneurs to start businesses. Innovation and entrepreneurship education should form innovative spirit, innovative ideas and knowledge capabilities through specific education. The current entrepreneurship management curriculum focuses on the study of basic knowledge, neglects the cultivation of students' creativity, and defies the training of students' creativity and innovative methods. It is related to the teacher's professional background and school curriculum design, and it is difficult to achieve the desired teaching effect.

3) The academic achievements of innovation and entrepreneurship education are broad

In the past ten years, the research results of innovation and entrepreneurship education in China have increased as a whole, but the following problems still exist. (1) the research direction is scattered, the focus is not high, and the research coverage is small. (2) with regard to the research on innovation and entrepreneurship education, vocational colleges and general undergraduate institutions are more valued than key institutions. (3) Academic achievements are concentrated in the field of social science research. There are a few concerns about the specific implementation path and effect evaluation of innovation and entrepreneurship education. Although the academic achievements of entrepreneurship education are rich, the authoritative textbooks or theories in the discipline have not been recognized by the industry. The textbooks used by various colleges have different shapes and different knowledge structures. Entrepreneurial management urgently needs authoritative and highly recognized academic achievements.

\section{B. Entrepreneurial management disciplines environmental issues}

\section{1) The curriculum design is not systematic}

At present, the major entrepreneurial management majors belong to the emerging disciplines. There are not many mature textbooks in China, the research points of academic achievements are scattered, and the quality of teaching materials is not uniform. The curriculum design lacks problems such as step by step and systematic process. The ultimate goal of innovation and entrepreneurship in colleges and universities is not to encourage students to start their own businesses, but to cultivate students' innovative ability and innovative consciousness through the dual role of institutional basic knowledge system learning and social practice activities. Therefore, the course design should be gradual, and the logical order from simple to complex should be deepened to accept entrepreneurship education. When the course is opened, it is necessary to combine compulsory, elective, general education and other courses to establish a multi-level and wide-ranging innovation and entrepreneurship curriculum system to form innovation and entrepreneurship and a virtuous circle of mutual integration and mutual development [4].

2) The development of entrepreneurial management disciplines is slow

There are still a few scholars paying attention to entrepreneurial management research in China. Although there are reform policies and talent measures for entrepreneurship education, compared with foreign entrepreneurship management teaching, it is still in the development stage. At this stage, it is not in line with the domestic university system and systematic entrepreneurial management teaching system, how to improve and innovate the existing entrepreneurial education model of the current colleges is the key to the establishment of entrepreneurship management curriculum and talent training programs. The problems existing in the establishment of entrepreneurship management courses in major universities in China include weak subject foundation, weak professional teachers, difficulty in establishing uniformity of teaching materials, and lack of close correlation between entrepreneurial management-related subjects [5].

3) The cultural environment of campus entrepreneurship is weak

The campus entrepreneurial culture atmosphere has an important impact on college students' entrepreneurial education. In general, the campus entrepreneurial culture atmosphere has the following positive impact on entrepreneurship education. (1) Promote the formation of college students' entrepreneurial consciousness. (2) Promote the formation of college students' entrepreneurial personality. (3) Promote the formation of college students' entrepreneurial ability. (4) Promote the entrepreneurial behavior of college students. At present, the entrepreneurial culture atmosphere of colleges and universities is relatively poor, students lack a correct understanding of entrepreneurial management education, and entrepreneurial desire is not high.

\section{THE PRACTICE TEACHING MODEL REFORM PROPOSALS}

According to interviews with 320 students from the Shanghai University of International Business and Economics, there are 144 students in the sophomore year and 176 in the fourth year. Among them, 76 are male students and 244 are female students. The interviews included students' views and suggestions on the Entrepreneurship Management course. The interview results show that sophomores hope to cultivate innovative consciousness and innovative thinking. Because of the employment pressure in the fourth grade, they hope to directly improve their professionalism and increase their job search opportunities. Therefore, the article summarizes the training objectives and teaching methods.

\section{A. Training objectives}

1) Improvement of the ability of lower grade students

The interview results show that $68 \%$ of the 144 students in the sophomore year think that they hope to focus on the theory of entrepreneurial management theory. They usually use the school competition or summer social practice to train 
entrepreneurial ability. $19 \%$ of the students think that entrepreneurship management should be a practical course, the theoretical knowledge structure is important but should not be focused. In normal times, the learning process should be based on practice. As the sophomores have just been exposed to professional courses, it is the ultimate goal of the curriculum to strengthen the awareness of innovation and cultivate entrepreneurial students with innovative thinking skills. The education of lower grade students focuses on the combing of knowledge and training their innovative thinking and ability. The ability to innovate mainly includes four aspects: learning ability, analytical ability, imagination ability and practical ability.

a) Learning ability. It refers to the ability to acquire and master knowledge, methods and experience, including reading, understanding, expression and memory. Learning ability is the core competitiveness of people, and it is an important reason to really open the gap between people. Entrepreneurs need to maintain a constant flow of curiosity and learning about new things and seize fleeting opportunities.

b) Analytical ability. It refers to the ability to decompose the problem into several parts and solve them one by one. Entrepreneurs need to deal with a lot of sudden and random problems, so it is important to have the ability to analyze problems and solve problems.

c) Imagination ability. It refers to the ability to propose new scenes and new ideas through intuition and image thinking based on certain knowledge and experience. Imagination can help entrepreneurs build a blueprint for future development, and entrepreneurs need bold assumptions and careful verification.

d) Practical ability. It refers to social practice ability. Entrepreneurs are good at turning ideas in their minds into reality. In order for the results to be recognized, entrepreneurs need to spread to the society, and their practical ability is being used.

2) Improvement of the professional quality of senior students

The fourth-grade students are looking for work in graduation. Their general appeal for entrepreneurship management education is to employment and enhances professional ability. The interview found that $83 \%$ of the 176 students in the fourth-grade hope to have a more competitive professional ability, $12 \%$ of the students hope to cultivate good professionalism from the first stage, and $5 \%$ of the students hope to start the course. It should be open for a while before coming into contact with the workplace. Therefore, for the special period of the fourth year, the training objectives should focus on the cultivation of professional ability and social practice ability. Entrepreneurial management professional competence should be the cultivation of entrepreneurial ability, that is, the ability to understand and create new things, and to disseminate and apply new results in a new field. The cultivation of this ability focuses on continuous investment in business sensitivity and practical ability. Therefore, entrepreneurial management professionals need not only to be familiar with the professional knowledge, but also have certain management and economic qualities. The entrepreneurial process actually involves all aspects of product development, production, and sales. Entrepreneurs should be familiar with every aspect of the entrepreneurial process. Entrepreneurship management students should have the ability to deal with real-world problems such as resource allocation, relevant decision-making and future development trends. Practical ability is the embodiment of entrepreneurial execution. Entrepreneurs need to have the practical ability to turn ideas into reality. This ability needs to be cultivated in practice, and the experience error can be summed up to find the fastest solution.

\section{3) Construction of comprehensive knowledge structure}

The content of "entrepreneurship and related content can be taught” is being accepted by more and more scholars. It is important for students to fully grasp the relevant knowledge of entrepreneurship management and to form a corresponding knowledge framework. The structure of entrepreneurial knowledge in the management of college students should include three dimensions: (1) Solid basic knowledge of economic management. (2) Expertise related to the entrepreneurial management profession, including literature and science. (3) Advanced knowledge to improve the sense of innovation. The management structure of economics and management should include economics, economic management, industrial policy, investment economics, statistics, accounting, management, human resources management, marketing, e-commerce, international trade, international finance et al. The professional knowledge is based on the comprehensive achievements of philosophy, economics, tourism management, logistics management, behavioral science and entrepreneurship; the advanced cultivation of innovation consciousness is essentially the cultivation of non-intellectual factors, and should be a persistent curiosity about new things. Questioning things and finding new ways to path for existing ones [6].

\section{B. Teaching methods}

\section{1) Establishment of knowledge structure for lower grade} students

The course of "Entrepreneurship Management" should be carried out in a step-by-step manner. The course setting includes compulsory courses, elective courses and general courses. Compulsory courses should be set in the sophomore year, and the seniors will be biased in application, such as practical courses or entrepreneurial success lectures, which are tailored to the needs of different grades and career development needs. Entrepreneurial management compulsory courses include entrepreneurship management, business communication and communication, strategic entrepreneurship et al. Compulsory courses include foreign language, statistics, network computing applications, et al. General courses include applied economics, management, finance, management science, et al. The theme of the lecture mainly focuses on the struggle experience of entrepreneurs and the history of corporate growth. The theoretical course knowledge should be arranged in the lower grades as much as possible, and the fourth-grade skills should be exercised in practice, encourage students to participate in social practice, and experience sharing sessions of successful people. 


\section{2) Strengthening of the social practice of senior students}

The ultimate goal of innovation and entrepreneurship education is to cultivate students' innovative thinking and innovative consciousness. Senior students should re-understand the entrepreneurial management knowledge system from social practice and process the learned income into their own views. Therefore, extracurricular practice has important practical significance and value as the result of theoretical learning. The extracurricular practice of entrepreneurship education in colleges and universities should be carried out in three aspects:

\section{3) Case teaching and theory}

Case teaching method is always used in entrepreneurship management education to help students understand professional knowledge in combination with specific application scenarios. As a practical practice, the dual-educational education has a large deviation from the traditional theoretical teaching and actual life. The case teaching method helps students understand the abstract concept and understand the knowledge concept involved in entrepreneurial practice activities. The application of case teaching in dual-education education has been discussed in detail by scholars. Wang et al. (2018) believe that the case teaching of entrepreneurship education should be carried out from three aspects: Firstly, perfect the case teaching implementation based on the training goal of innovative entrepreneurs. Secondly, is to establish a high-level case creation team that meets the teaching objectives; thirdly, it should combine the flipping classroom to carry out case teaching based on innovation and entrepreneurship education [7]. In addition, in the teaching mode, you can refer to the $\mathrm{O} 2 \mathrm{O}$ teaching mode, that is, classroom learning and online learning of multimedia resources as a student's undergraduate learning task. Entrepreneurial management education cases should focus on selecting entrepreneurial experiences in the industry, including the way companies respond to problems such as decision-making and crisis.

\section{Performance assessment}

Courses are qualified, and the corresponding grades, grade points and credit scores should be strictly implemented in accordance with the relevant provisions of the "General Rules for the Teaching and Learning Program of Credit System in Colleges and Universities", "Regulations on the Management of Academic Credits in Colleges and Universities" and "Administrative Measures for the Examination of Colleges and Universities". The practical credits should be increased according to the students' participation in the innovation and entrepreneurship competition inside and outside the class. The practical credits should also be completed according to the requirements of the corresponding credit system. The performance appraisal aims to urge students to complete the stage in strict accordance with the teaching methods and curriculum of the institutions.

\section{CONCLUSION}

The article interviewed 320 students in the entrepreneurship management course. The interview results show that the lower grade students pay attention to the establishment of the knowledge system structure, and the senior students tend to train the practical using ability of knowledge. In addition, from the perspectives of teachers and subject environment, this paper analyzes the problems faced by the practical teaching of entrepreneurship management courses. The teacher level is mainly lack of professional teachers, deviation of entrepreneurial education concepts, and less academic achievements. The major environmental aspects of the discipline are mainly the lack of systematic design of the curriculum, the slow development of the discipline, and the weak cultural atmosphere of campus entrepreneurship. To this end, combined with the different professional training needs of high and low grades, the main purpose is to establish a theoretical knowledge structure for the lower grades, and the senior grades combine the training objectives, teaching methods and performance assessments with the important training methods of social practice to construct the practical teaching mode of "Entrepreneurial Management" curriculum, providing reference for cultivating entrepreneurial management talents.

\section{REFERENCES:}

11 L.Yang, K. G. Chen. Research on the Reform of Innovation and Entrepreneurship Management Course[J]. China Market, 2018, No.980(25), pp. 176-177.(In Chinese)

[2] Z. Y. Guo. Practice and Thinking of Teaching Reform of Entrepreneurial Management Course[J]. Modern Education Science, 2017(8).(In Chinese)

3] T. Q. Zhang, Q. He. The Construction of College Students' Entrepreneurial Management Course and the Cultivation of Advanced Ability-Taking Tianjin University of Traditional Chinese Medicine as an Example[J]. University Education, 2017(10), pp.156-158. (In Chinese)

[4] P. Shen. Reflections on Strengthening the Management of Innovation and Entrepreneurship in Colleges and Universities [J]. Reading and Writing (Education and Teaching Journal), 2016(10). (In Chinese)

[5] Z. C. Yan, Y. Q. He. Research on Teaching Innovation of College Students' Entrepreneurial Management Course Based on CDIO Concept[J]. Education and Teaching Forum, 2016(49), pp.59-61. (In Chinese)

[6] X. W. Hu. Study on Knowledge Structure of Quality and Ability of Management and Entrepreneur Talents in Economic Management[J].Journal of Nanchang Teachers College, 2008, 29(4), pp.26-29. (In Chinese)

[7] X. L. Wang, S. Deng, D. Yu, J. Sun, X. R. Liu. Application of Case Teaching in Universal Innovation and Entrepreneurship Education[J]. Chinese Character Culture, 2018, 216(22), pp.123-124+127. (In Chinese) 